\title{
Brain Circuitry for Arousal from Apnea
}

\author{
Clifford B. SAPer and Satvinder KauR \\ Department of Neurology, Division of Sleep Medicine, and Program in Neuroscience, Beth Israel \\ Deaconess Medical Center and Harvard Medical School, Boston, Massachusetts 02215, USA
}

Correspondence: csaper@bidmc.harvard.edu

\begin{abstract}
We wanted to understand the brain circuitry that awakens the individual when there is elevated $\mathrm{CO}_{2}$ or low $\mathrm{O}_{2}$ (e.g., during sleep apnea or asphyxia). The sensory signals for high $\mathrm{CO}_{2}$ and low $\mathrm{O}_{2}$ all converge on the parabrachial nucleus (PB) of the pons, which contains neurons that project to the forebrain. So, we first deleted the vesicular glutamate transporter 2, necessary to load glutamate into synaptic vesicles, from neurons in the $\mathrm{PB}$, and showed that this prevents awakening to high $\mathrm{CO}_{2}$ or low $\mathrm{O}_{2}$. We then showed that $\mathrm{PB}$ neurons that express calcitonin gene-related peptide (CGRP) show cFos staining during high $\mathrm{CO}_{2}$. Using CGRP-Cre-ER mice, we expressed the inhibitory opsin archaerhodopsin just in the PB ${ }^{\mathrm{CGRP}}$ neurons. Photoinhibition of the $\mathrm{PB}^{\mathrm{CGRP}}$ neurons effectively prevented awakening to high $\mathrm{CO}_{2}$, as did photoinhibition of their terminals in the basal forebrain, amygdala, and lateral hypothalamus. The $\mathrm{PB}^{\mathrm{CGRP}}$ neurons are a key mediator of the wakening response to apnea.
\end{abstract}

As a person falls asleep, there is a gradual loss of muscle tone in the airway dilator muscles. In individuals who have obstructive sleep apnea (OSA), usually due to narrow airways, this may cause the tongue to extend back, occluding the airway (White and Younes 2012; White 2016). The person continues to try to breathe with greater and greater efforts but no airflow, until at some point there is an arousal, with electroencephalogram (EEG) desynchronization indicative of waking up. At this point, there is a sudden increase in tone in the airway dilator muscles, reopening the airway. The OSA patient then continues to breathe, falls asleep again, and the cycle repeats. In a typical OSA patient this may occur hundreds of times over the course of the night, leading to fragmented sleep as well as deleterious cognitive, metabolic, and cardiovascular side effects (Framnes and Arble 2018; Gaines et al. 2018; Olaithe et al. 2018).

OSA is often treated with continuous positive airway pressure (CPAP), which stents the airway open. Although this is effective, it requires sleeping with a mask and a machine that causes continuous airway flow (and noise). Many unfortunate OSA patients cannot tolerate the CPAP apparatus, and it is cumbersome to take with when traveling (White 2016). Hence, a way to treat OSA that manipulated the brain circuitry that controls airway musculature and arousal during sleep would be of value.

Unfortunately, until quite recently not much was known about this circuitry. During apnea, there are three main sensory stimuli that alert the brain (Fig. 1; Gleeson et al. 1990). Hypoxia is sensed primarily by the carotid body, which transmits that information to the nucleus of the solitary tract (NTS) via the carotid sinus branch of the glossopharyngeal nerve (Lindsey et al. 2018). The carotid body also recognizes hypercarbia (elevated $\mathrm{CO}_{2}$ ) via the same mechanism and is sensitized to this during hypoxia (Nurse and Piskuric 2013). In addition, there are a number of neuronal types in the CNS that also sense high $\mathrm{CO}_{2}$ directly. One of these is the retrotrapezoid nucleus in the base of the pons (Guyenet et al. 2016). The retrotrapezoid nucleus and the NTS send major axonal outputs to the ventrolateral medulla (VLM), which contains the pattern generator for breathing, and the ventrolateral part of the parabrachial nucleus (PB), an important relay for visceral sensory information from the brainstem to the forebrain (Guyenet et al. 2010). Other $\mathrm{CO}_{2}$ sensing neurons are found in the serotonergic raphe system in the brainstem and in the orexin neurons in the lateral hypothalamus (Severson et al. 2003; Corcoran et al. 2009; Burdakov et al. 2013). Interestingly, these neurons also project to the NTS, the VLM, and the PB. In fact, in animals that have been exposed to elevated $\mathrm{CO}_{2}$ or to hypoxia or to intermittent airway occlusion, there is characteristic distribution of expression of cFos, an immediate early gene marking neurons that have been activated. In these animals, cFos is expressed in the retrotrapezoid nucleus, the NTS, the VLM, and the ventrolateral PB (Teppema et al. 1997; Berquin et al. 2000; Ferreira et al. 2015).

A third source of sensory input during apnea is generated by the hypoxia and hypercarbia causing increased respiratory effort, which produces negative pressure in the airway. This is registered by mechanoreceptor fibers in the vagus nerve, which also terminate in the same part of the NTS as the chemoreceptor inputs. cFos studies in animals with stimulation of the airway mechanoreceptors shows the same pattern of cFos expression as in hypoxia or hypercarbia, involving the NTS, VLM, and ventrolateral PB (Gestreau et al. 1997). In humans with OSA, the timing of arousal correlates most closely with the airway negative pressure, a bit less well with the degree of hypercarbia, and least well with the level of hypoxia (Gleeson et al. 1990). However, the degree of ventilatory effort is a complex function of the hypercarbia and hypoxia, and all

(C) 2018 Saper and Kaur. This article is distributed under the terms of the Creative Commons Attribution-NonCommercial License, which permits reuse and redistribution, except for commercial purposes, provided that the original author and source are credited. 
A
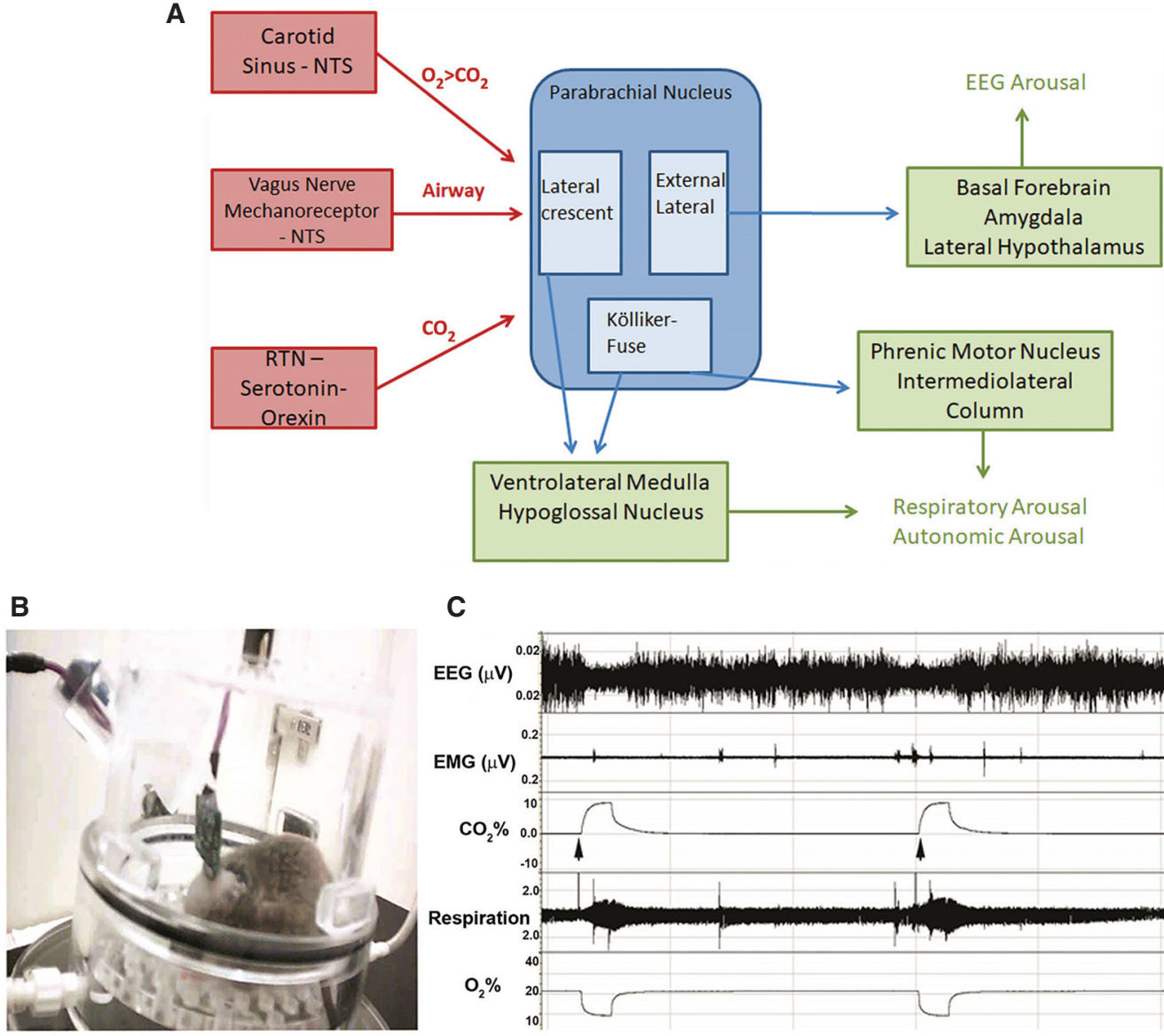

C

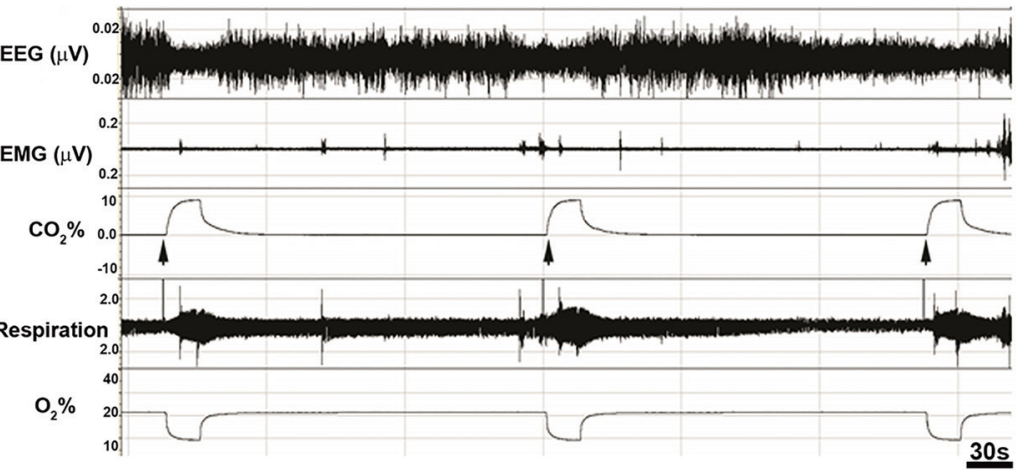

Figure 1. (A) Schematic representation showing the convergence of the major three sensory stimuli during apnea on the parabrachial area (PB). The carotid body senses both hypoxia and hypercarbia, and relays to the nucleus of the solitary tract (NTS) via the glossopharyngeal nerve. The NTS also receives mechanosensory input such as negative inspiratory pressure from the airways. Increased pCO $\mathrm{pls}_{2}$ activates central chemoreceptors in the retrotrapezoid nucleus (RTN), as well as raphe serotonergic neurons and hypothalamic orexin neurons. All of these outputs converge on the ventrolateral corner of the parabrachial nucleus (PB), which includes three subnuclei. The external lateral subnucleus projects to the forebrain to cause cortical arousal through projections to the lateral hypothalamus, basal forebrain, and amygdala. The lateral crescent and Kölliker-Fuse (KF) nuclei project to respiratory and autonomic control sites in the brainstem and spinal cord. $(B, C)$ A mouse model of apnea. A mouse is allowed to sleep in a plethysmograph chamber $(B)$ while EEG, EMG and breathing are recorded $(C)$. The mouse is intermittently exposed to bouts of $10 \% \mathrm{CO}_{2}$ (hypercapnia), hypoxia, or both given every $5 \mathrm{~min}$ for $30 \mathrm{sec}$. During these trials, the arousals are judged by EEG desynchronization (loss of delta waves and appearance of low voltage, fast EEG), which is usually accompanied by EMG activation. Mice undergo spontaneous periods of sleep and wake; however, only trials where the mouse is in NREM sleep for at least $30 \mathrm{sec}$ before onset of the $\mathrm{CO}_{2}$ are used to examine arousal. (Adapted and modified from Kaur et al. 2013.)

three measures converge in the same brain locations. So, studying these connections is likely to yield important information about the brain response to apnea.

The PB is a particularly likely spot to integrate these signals and control both the respiratory and arousal responses to apnea. The PB was identified as early as the 1920 s as a key area for respiratory control (Lumsden 1923), and the ventrolateral part of it has been called the "pneumotaxic center" or the "pontine respiratory group" (Feldman 1986). It contains two main components: (1) neurons in the medial $\mathrm{PB}(\mathrm{PBm})$ and the external lateral $\mathrm{PB}(\mathrm{PBel})$ subnuclei project to the forebrain and we hypothesized that they may have a role in arousal during apnea; and (2) neurons in the far lateral PB, including the lateral crescent (PBlc) and Kölliker-Fuse (KF) nucleus project to the NTS, VLM, and respiratory motor groups such as the hypoglossal nucleus (necessary to control tongue motor tone that keeps the airway open), and phrenic motor nucleus (which controls the diaphragm) (Saper and Loewy 1980; Fulwiler and Saper 1984; Herbert et al. 1990; Moga et al. 1990).

To test the effects of manipulating this circuitry on arousal during apnea, we developed a mouse model. Because rodents do not have occlusion of the airway during sleep, we placed the mice in a plethysmographic chamber, where we could also record their EEG and electromyography (EMG) to monitor wake-sleep (Fig. 1B,C). Every $5.5 \mathrm{~min}$, we changed the gas mixture in the cham- 
ber, either to hypoxic $\left(10 \% \mathrm{O}_{2}\right)$, hypercarbic $\left(10 \% \mathrm{CO}_{2}\right)$, or both (Fig. 1C), for $30 \mathrm{sec}$ (Kaur et al. 2013). It took 10 sec for the gas mixture to asymptotically approach the target level, and mice would consistently awaken after 10-20 sec of exposure to the new gas mixture.

As most neurons in the PB are glutamatergic, we initially used mice with flanking loxP sites around the second exon of the vesicular glutamate transporter 2 gene (Vglut $2^{\text {flox/flox }}$ mice), and injected the PB with an AAV that expressed both Cre recombinase and Venus green protein (Kaur et al. 2013). We found that injections that removed functional Vglut2 from the far ventrolateral $P B$, including the PBel, PBlc, and KF, dramatically lengthened the time it took animals to arouse to either hypoxia, hypercarbia, or both, to well beyond the 30 -sec gas exposure (indicating that most of their eventual arousals were spontaneous, not gas-induced) (Fig. 2). Because human awakening during apnea mainly corresponds to hypercarbia (Gleeson et al. 1990), subsequent experiments were done using just hypercarbia as a stimulus (Kaur et al.
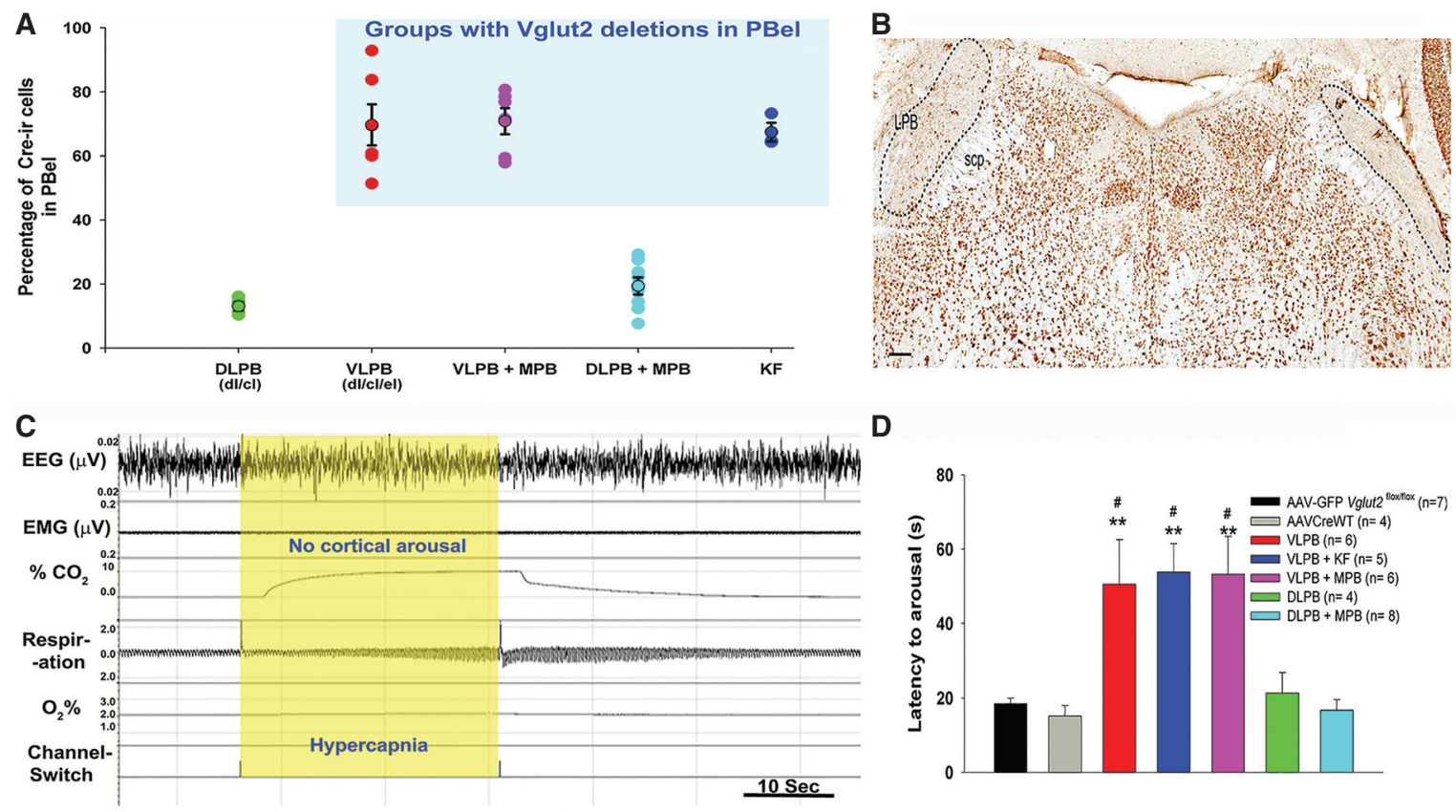

D
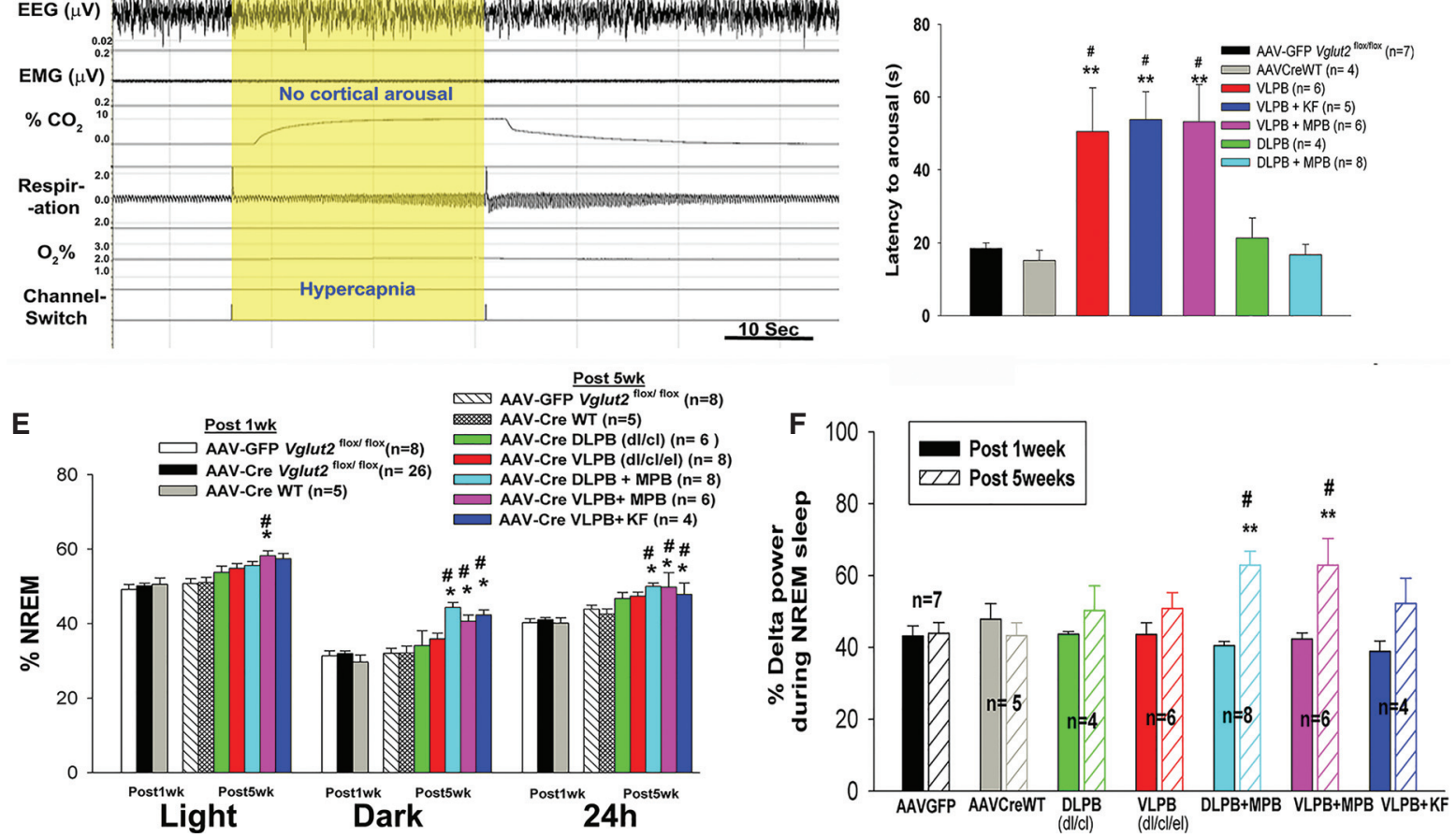

Figure 2. Testing the role of glutamatergic signaling from the PBel in hypercapnia-induced arousal. $(A)$ The numbers of the Cretransduced neurons in the external lateral parabrachial nucleus (PBel) region after injection of AAV-Cre in Vglut $2^{\text {flox/flox }}$ mice. The groups coded by red, purple, and dark blue in the rest of the figure had by far the largest numbers of neurons in which Vglut 2 was deleted from the PBel. $(B)$ A photomicrograph of a brain section immunostained for Neu-N, a neuronal marker after bilateral injection of AAV-DTA killed Vglut2+ neurons into the lateral PB of a Vglut2-Cre mouse. (C) A representative trial from a mouse with deletion of the $V$ glut2 gene in the LPB that failed to wake up to hypercapnia but showed an intact ventilatory response as can be seen by gradual increase in respiration with increasing $\mathrm{CO}_{2}$ levels. $(D)$ Graph showing that the latency to arousal with $\mathrm{CO}_{2}$ was much longer in the groups where there was deletion of glutamatergic signaling in the PBel (shown by blue box in $A$ and are represented by red, blue, and magenta in graph $D)$. (E) Compares the percentage amount of sleep in different groups of mice during the light, dark period and then compared for average over $24 \mathrm{~h}$. Delta power during the NREM, which is an indicator of the depth of sleep, is compared in $F$. Mice with deletions of the Vglut2 gene in the medial PB (cyan, magenta, and blue) had significantly increased NREM sleep and EEG delta power during NREM. (scp) Superior cerebellar peduncle, (LPB) lateral parabrachial nucleus. Scale $=100 \mu \mathrm{m}$. ** and $*$ represent $P<0.01$ and $P<$ 0.05 respectively, compared to the control group (AAV-GFP) and (\#) $P<0.05$, compared to the AAVCreWT group. (Adapted and modified from Kaur et al. 2013.) 
2013). Vglut2 deletion in the PBm did not affect time to wakening during either hypoxia or hypercarbia but did increase baseline sleep in the animals by $\sim 17 \%$ during the light phase and by $24 \%$ in $24 \mathrm{~h}$ (Fig. 2E,F). We then used Vglut2-Cre mice which we injected with AAV-FLEX-DTA (for Cre-dependent expression of diphtheria toxin A, which kills the cells that express Cre) (Fig. $2 \mathrm{~B})$. The results were almost identical, indicating that the removing glutamate as a neurotransmitter from ventrolateral PB cells has the same effect in preventing $\mathrm{CO}_{2}$ arousal as killing the cells (i.e., glutamate is their main neurotransmitter [Kaur et al. 2013]).

Because many of the cells in the PBel that show cFos expression after $\mathrm{CO}_{2}$ exposure contain the neuropeptide CGRP (calcitonin gene-related peptide) (Kaur et al. 2017), we next use CGRP-Cre-ER mice to determine if these neurons played a part in $\mathrm{CO}_{2}$ arousal. To inhibit just the CGRP neurons in the PBel we injected AAV containing the gene for archaerhodopsinT (ArchT)-GFP in the CGRP group in CGRP-Cre-ER mice, which caused those cells to express ArchT, an inhibitory optogenetic proton pump (Fig. 3A; Kaur et al. 2017). We then activated the ArchT with a 593-nm orange laser, which was turned on $20 \mathrm{sec}$ before the $\mathrm{CO}_{2}$ trial, and continued for $60 \mathrm{sec}(10 \mathrm{sec}$ after the gas exchange reverted to room air, and about the time that the level of $\mathrm{CO}_{2}$ returned to $<1 \%$ ) (Fig. 3C). We found that in a slice preparation, subjecting ArchT-expressing $\mathrm{PB}^{\mathrm{CGRP}}$ neurons to 593-nm laser light completely silenced their firing (Fig. 3B).

Inhibition of $\mathrm{PB}{ }^{\mathrm{CGRP}}$ neurons with ArchT was as effective at delaying EEG arousal to $\mathrm{CO}_{2}$ as was killing or deleting Vglut2 from a much larger number of neurons in the ventrolateral quadrant of the PB (Fig. 3C,D; Kaur et al. 2017). Moreover, it did not affect the increase of the ventilatory rate, depth, or respiratory airway muscle tone, which still occurred during $\mathrm{CO}_{2}$ stimulation (Fig. 4). We next inhibited the terminals of the $\mathrm{PB}^{\mathrm{CGRP}}$ neurons in the forebrain using ArchT. We found that inhibiting the basal forebrain terminals (in the substantia innominata, just ventral to the head of the globus pallidus) delayed the onset of EEG arousal to $\mathrm{CO}_{2}$ by $\sim 70 \%$ of the amount of inhibiting the $\mathrm{PB}^{\mathrm{CGRP}}$ cell bodies (Fig. 3E). Because this part of the basal forebrain contains many cortically projecting neurons whose activity is important for cortical arousal, we hypothesize that this is the main target of the PB ${ }^{\text {CGRP }}$ neurons. However, we obtained smaller delays in the arousal to $\mathrm{CO}_{2}$ from inhibiting $\mathrm{PB}^{\mathrm{CGRP}}$ terminals in the central nucleus of the amygdala $(\sim 50 \%)$ and the lateral hypothalamic area (about 30\%) (Fig. 3D). As the central nucleus has no ascending projections to the cortex or thalamus (Price and Amaral 1981), we believe that it influences arousal to $\mathrm{CO}_{2}$ by means of its potent projection to the basal forebrain (Kaur et al. 2017). The lateral hypothalamic influence on $\mathrm{CO}_{2}$ arousal may also relay in the basal forebrain, although there are direct projections to the cerebral cortex from lateral hypothalamic neurons that contain orexin, melanin-concentrating hormone, glutamate, or histamine.

We are also concerned about the role of the PB in causing the increases in airway motor tone that allow reopening of the airway during apneas. Although inhibiting the $\mathrm{PB}^{\mathrm{CGRP}}$ neurons prevented EEG arousal to $\mathrm{CO}_{2}$, it had no effect on the respiratory response (Fig. 4). Just lateral to the PB ${ }^{\text {CGRP }}$ group is a separate population of neurons, most of which express the transcription factor FoxP2 and which show cFos expression during $\mathrm{CO}_{2}$ exposure (Geerling et al. 2017). These neurons in the KF and PBlc wrap around the lateral border of the PBel and invade the central lateral PB subnucleus. They are known to project extensively to the VLM, the NTS, and the hypoglossal and phrenic motor nuclei. We are currently working on the role these neurons play in respiratory versus EEG arousal to $\mathrm{CO}_{2}$.

Another population of neurons that play a key role in the brain response to $\mathrm{CO}_{2}$ is the brainstem raphe serotonin neurons. In experiments with knockout of Pet1, a key transcription factor for development of the serotonin neurons, there is failure for the serotonin neurons to form, and the animals have neither EEG arousal nor ventilatory response to $\mathrm{CO}_{2}$ (Buchanan and Richerson 2010; Hodges et al. 2011; Ray et al. 2011; Brust et al. 2014). In the medulla, Pet1 neurons also express either Egr2 (upper medullary raphe) or Tac1 (lower medullary raphe). By using intersectional genetics, Dymecki and colleagues showed that loss of either of these two populations will reduce the ventilatory, but not the EEG arousal, response to $\mathrm{CO}_{2}$ (Brust et al. 2014; Hennessy et al. 2017).

The origin of the serotonin role in the EEG arousal response to $\mathrm{CO}_{2}$ has recently been identified by Buchanan and Richerson (2010). They showed that the neurons of the dorsal raphe, a rostral brainstem cell group that expresses neither Egr2 nor Tac, are directly responsive to acid or to elevated $\mathrm{CO}_{2}$ (which increases acidity) (Smith et al. 2018). The same group also showed that injection of a 5HT2a agonist into Pet1ko mice restored the responsiveness of EEG arousal, but not ventilatory effort, to $\mathrm{CO}_{2}$ exposure. These observations suggest the existence of a projection from the DR to a key target or targets that use 5HT2a receptors, and which then play a key role in $\mathrm{CO}_{2} \mathrm{EEG}$ arousal (Fig. 5). We are currently testing this hypothesis.

In summary, the currently available data support a model in which the key brain system for both EEG arousal and ventilatory response to $\mathrm{CO}_{2}$ involves convergence of information about hypoxia, hypercarbia, and airway mechanoreceptors in the ventrolateral quadrant of the PB. In this region, CGRP-expressing, glutamatergic neurons in the PBel appear to be the critical link between the brain sensory systems that detect apnea and the forebrain arousal circuitry that causes EEG arousal.

The serotonin system appears, in contrast, to play a modulatory role, in that it is not necessary for sensing hypercapnia, but is normally required for the PB ${ }^{\text {CGRP }}$ and $\mathrm{PB}^{\mathrm{FoxP2}}$ neurons and for the brainstem ventilatory system to respond to $\mathrm{CO}_{2}$. However, the ability to replace the effect of the serotonin neurons on EEG arousal to $\mathrm{CO}_{2}$ with a 5HT2a agonist drug suggests that the serotonin system is facilitatory, but it is not required to carry the signal for the $\mathrm{CO}_{2}$ level to achieve EEG arousal.

Better understanding of these parallel pathways that underlie the EEG arousal and airway dilator muscle response to $\mathrm{CO}_{2}$ will be useful in allowing us to design pharmaco- 
A
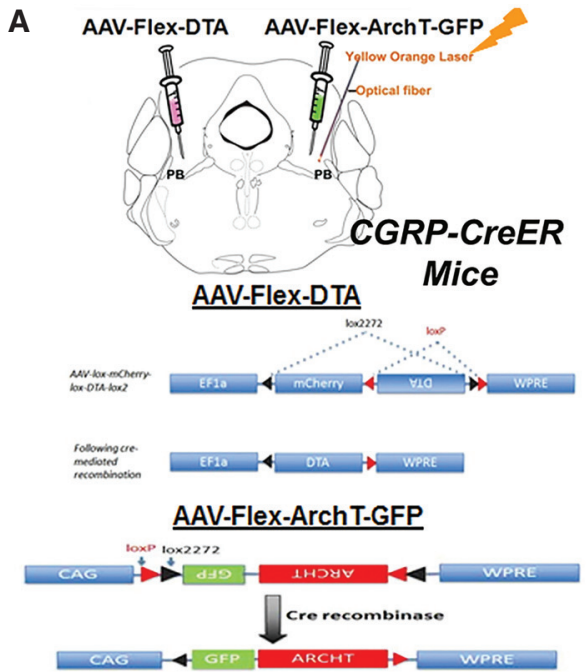

C
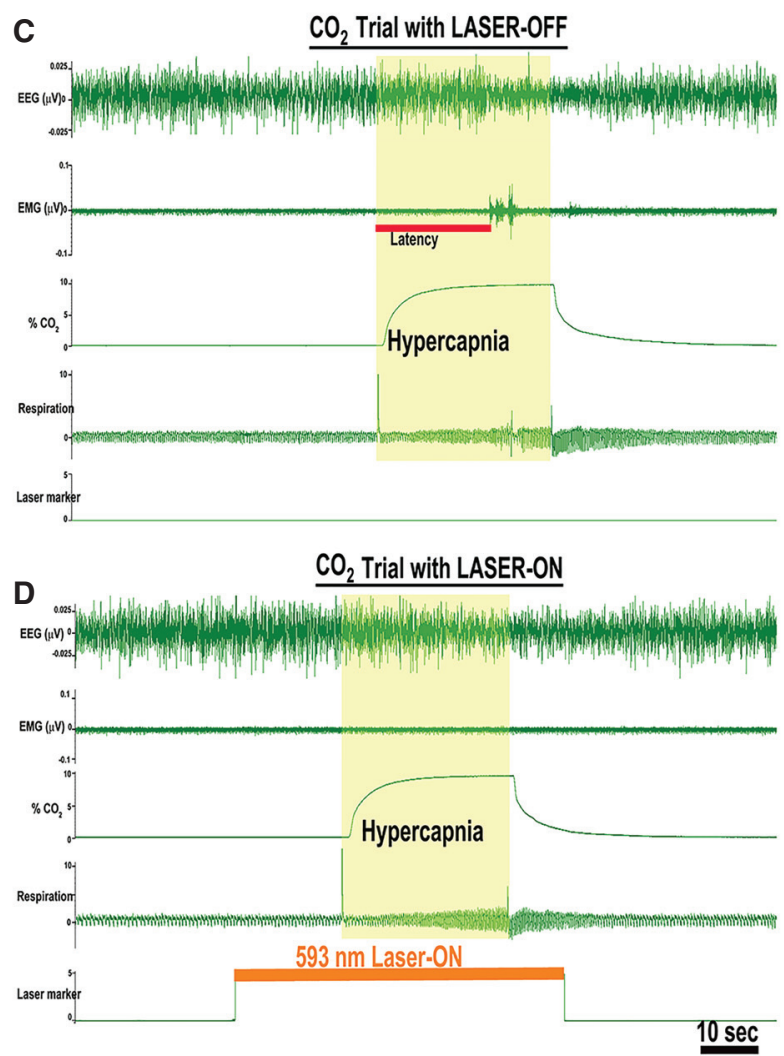

B
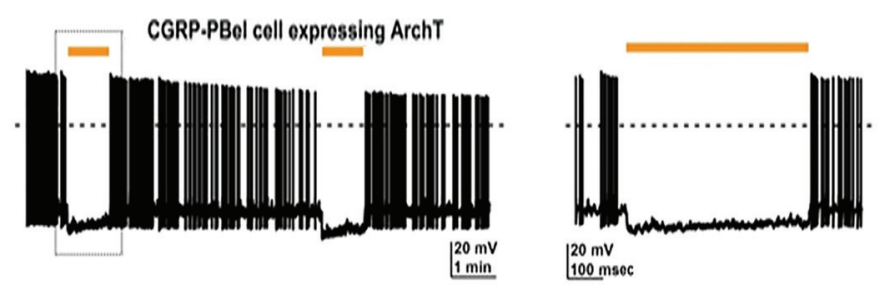

CGRP.PBel- expressing GFP (Control)
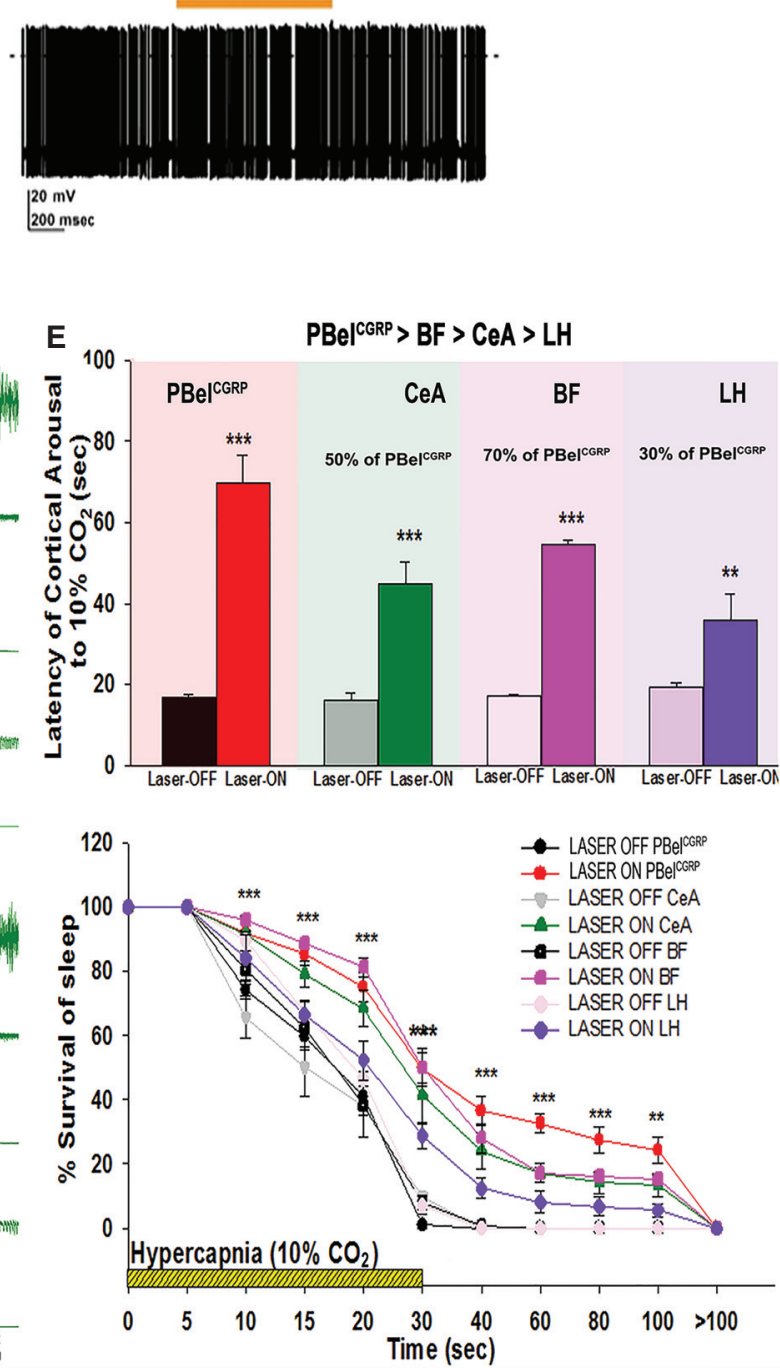

Figure 3. Selective silencing of the $\mathrm{PB}^{\mathrm{CGRP}}$ neurons and the terminal fields using optogenetics. $(A)$ The strategy to inhibit the PBel ${ }^{\mathrm{CGRP}}$ cells that express the inhibitory opsin archaerhodopsin (ArchT) by orange-yellow laser light $(593 \mathrm{~nm}$ ) on one side of the brain of a CGRP-CreER mouse injected with AAV-Flex-ArchT, while deleting the PB ${ }^{C G R P}$ neurons on the contralateral by injecting a diphtheria toxin viral vector that kills the cells in a Cre-dependent manner (AAV-Flex-DTA). (B) The in vitro validation of the silencing of the $\mathrm{PBel}^{\mathrm{CGRP}}$ neurons expressing ArchT. The same laser light produced no changes in the firing rate of $\mathrm{PB}^{\mathrm{CGRP}}$ neurons that expressed GFP (mice injected with AAV-Flex-GFP). (C) A representative recording of EEG, EMG, and respiration during the $10 \% \mathrm{CO}_{2}$ stimulus in a CGRP-CreER mouse with no-laser photoinhibition (Laser-OFF, where mouse wakes up in $18 \mathrm{sec}$ ), whereas in $D$, the same mouse is exposed to the yellow laser light during the $\mathrm{CO}_{2}$ trial (Laser-ON), and the mouse did not wake up to $\mathrm{CO}_{2}$, but had intact ventilatoryresponse to $\mathrm{CO}_{2}$, similar to the control with Laser-OFF. $(E)$ A comparison of the effects of PB ${ }^{\mathrm{CGRP}}$ soma inhibition to that of inhibiting PBel ${ }^{\mathrm{CGRP}}$ terminals in the CeA, BF, and LH. (Top) Latency of arousal to $\mathrm{CO}_{2}$ (mean $\pm \mathrm{SEM}$ ) with Laser-OFF or during Laser-ON. (Bottom) Survival of sleep curves during and after a hypercapnic stimulus shown with and without laser. $(* * *) P<0.0001 ;(* *) P<$ $\left.0.001 ;{ }^{*}\right) P<0.05$, one-way or repeated measures ANOVA followed by Holm-Sidak for multiple comparison. (Adapted and modified from Kaur et al. 2017.) 
A
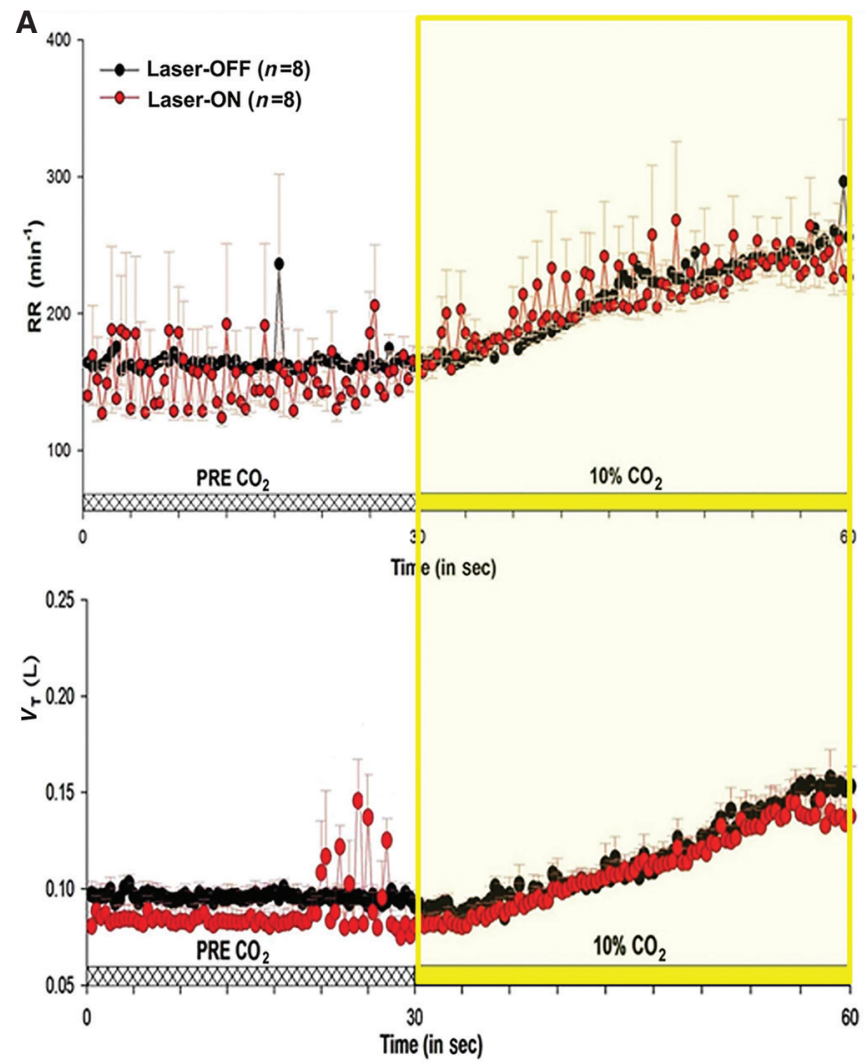
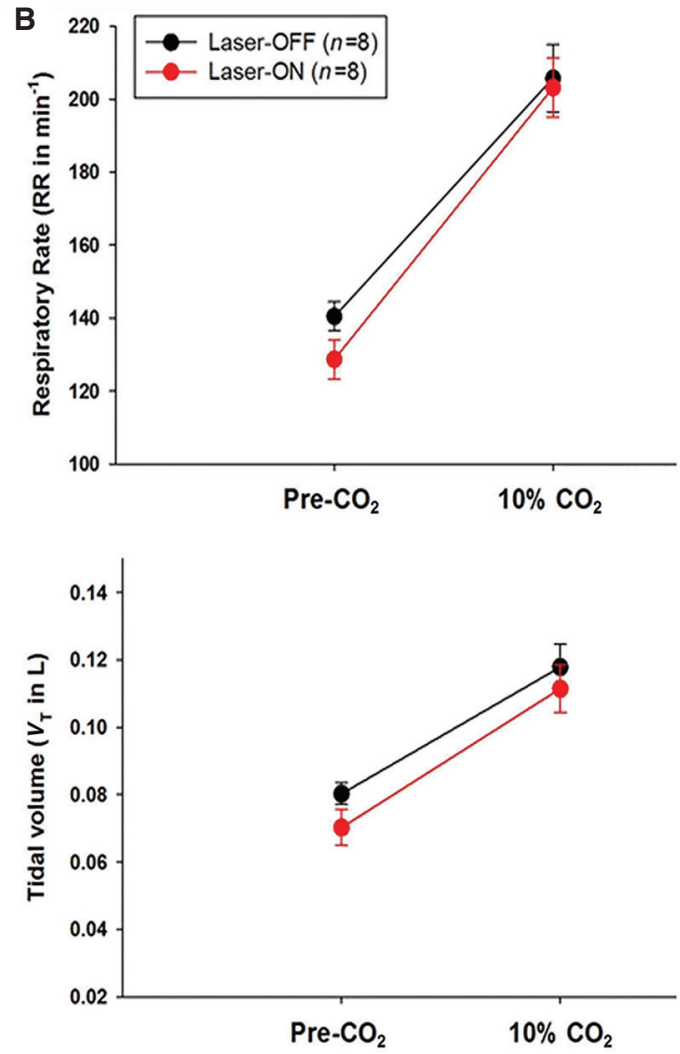

Figure 4. Selective silencing of the $\mathrm{PB}^{\mathrm{CGRP}}$ neurons did not change the ventilatory kinetics in response to $\mathrm{CO}_{2}$. $(A)$ Graphs showing respiratory rate $(\mathrm{RR})$ and tidal volume $\left(V_{\mathrm{T}}\right)$ for every breath, $30 \mathrm{sec}$ before the onset of $\mathrm{CO}_{2}$ and for $30 \mathrm{sec}$ during the $\mathrm{CO}_{2}$ trials, in Laser$\mathrm{OFF}$ and Laser-ON conditions, for the mice in which the PB ${ }^{\mathrm{CGRP}}$ neurons were injected with the inhibitory opsin ArchT to photoinhibit the PB ${ }^{\mathrm{CGRP}}$ neurons. $(B)$ Graphs comparing the RR and $V_{\mathrm{T}}$ for three breaths before $\mathrm{CO}_{2}\left(\mathrm{Pre} \mathrm{CO}_{2}\right)$ and for three breaths during $\mathrm{CO}_{2}$ just before waking up in Laser-OFF and then at the same time point in trials in the same animal with Laser-ON (in which the animals did not awaken). (Adapted and modified from Kaur et al. 2017.)

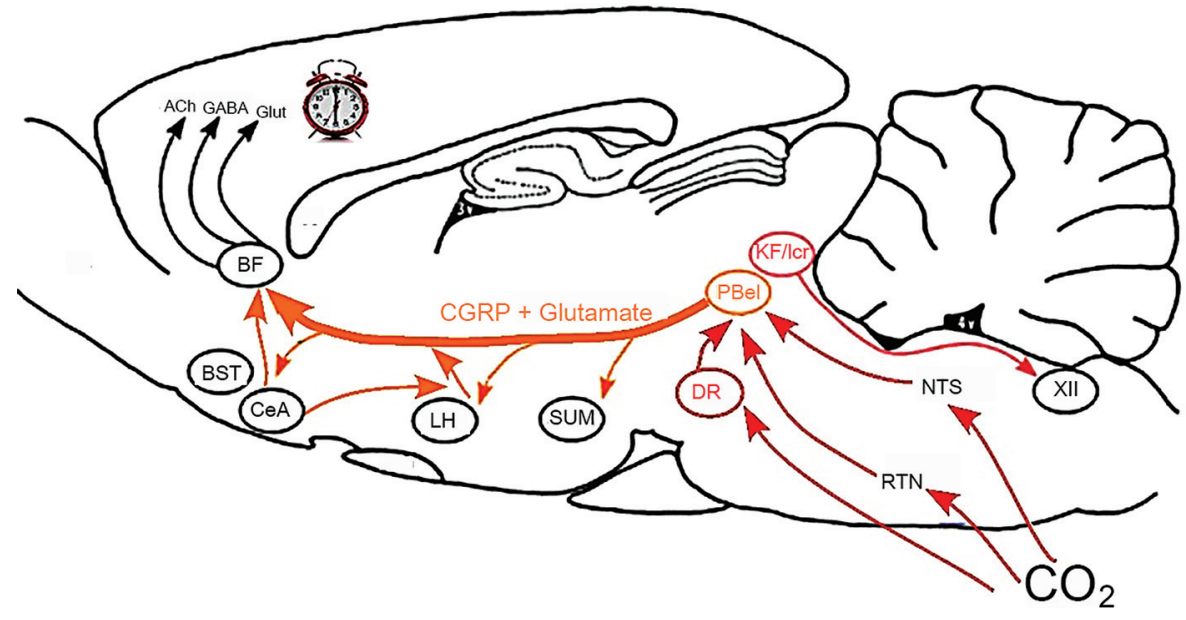

Figure 5. Neural circuit for arousal from apnea: $\mathrm{PBel}^{\mathrm{CGRP}}$ neurons receive $\mathrm{CO}_{2}, \mathrm{O}_{2}$, and airway mechanoreceptor inputs via the nucleus of solitary tract (NTS) and retrotrapezoid nucleus (RTN). The PBel ${ }^{\mathrm{CGRP}}$ neurons in turn project extensively to the lateral hypothalamus $(\mathrm{LH})$, basal forebrain $(\mathrm{BF})$, and central nucleus of amygdala (CeA) and bed nucleus of the stria terminalis (BST). Based on our findings, $\mathrm{PBel}{ }^{\mathrm{CGRP}}$ neurons mainly cause cortical arousal by projections to the $\mathrm{BF}$, which has more potent waking effects than PB ${ }^{\mathrm{CGRP}}$ inputs to the $\mathrm{CeA}$ and LH. The serotonergic dorsal raphe neurons (DR) modulate the arousal through their input to the PBel ${ }^{\text {CGRP }}$ neurons. $^{2}$ 
logical approaches that can suppress the EEG arousal, while sensitizing the ventilatory response and perhaps preventing the airway closure altogether.

\section{REFERENCES}

Berquin P, Bodineau L, Gros F, Larnicol N. 2000. Brainstem and hypothalamic areas involved in respiratory chemoreflexes: a Fos study in adult rats. Brain Res 857: 30-40. doi:10.1016/ S0006-8993(99)02304-5

Brust RD, Corcoran AE, Richerson GB, Nattie E, Dymecki SM. 2014. Functional and developmental identification of a molecular subtype of brain serotonergic neuron specialized to regulate breathing dynamics. Cell Rep 9: 2152-2165. doi:10.1016/ j.celrep.2014.11.027

Buchanan GF, Richerson GB. 2010. Central serotonin neurons are required for arousal to $\mathrm{CO}_{2}$. Proc Natl Acad Sci 107: 16354-16359. doi:10.1073/pnas.1004587107

Burdakov D, Karnani MM, Gonzalez A. 2013. Lateral hypothalamus as a sensor-regulator in respiratory and metabolic control. Physiol Behav 121: 117-124. doi:10.1016/j.physbeh .2013 .03 .023

Corcoran AE, Hodges MR, Wu Y, Wang W, Wylie CJ, Deneris ES, Richerson GB. 2009. Medullary serotonin neurons and central $\mathrm{CO}_{2}$ chemoreception. Respir Physiol Neurobiol 168: 49-58. doi:10.1016/j.resp.2009.04.014

Feldman JL. 1986. Neurophysiology of breathing in mammals. In Handbook of physiology - the nervous system IV-intrinsinc regulatory systems of the brain (ed. Bloom $\mathrm{FE}$ ), pp. 463-524. American Physiological Society, Washington, DC.

Ferreira CB, Schoorlemmer GH, Rossi MV, Takakura AC, Barna BF, Moreira TS, Cravo SL. 2015. Brainstem areas activated by intermittent apnea in awake unrestrained rats. Neuroscience 297: 262-271. doi:10.1016/j.neuroscience.2015.04.007

Framnes SN, Arble DM. 2018. The bidirectional relationship between obstructive sleep apnea and metabolic disease. Front Endocrinol 9: 440. doi:10.3389/fendo.2018.00440

Fulwiler CE, Saper CB. 1984. Subnuclear organization of the efferent connections of the parabrachial nucleus in the rat. Brain Res Brain Res Rev 7: 229-259. doi:10.1016/01650173(84)90012-2

Gaines J, Vgontzas AN, Fernandez-Mendoza J, Bixler EO. 2018 Obstructive sleep apnea and the metabolic syndrome: the road to clinically-meaningful phenotyping, improved prognosis, and personalized treatment. Sleep Med Rev 42: 211-219. doi:10.1016/j.smrv.2018.08.009

Geerling JC, Yokota S, Rukhadze I, Roe D, Chamberlin NL. 2017. Kölliker-Fuse GABAergic and glutamatergic neurons project to distinct targets. J Comp Neurol 525: 1844-1860. doi:10.1002/cne. 24164

Gestreau C, Bianchi AL, Grélot L. 1997. Differential brainstem fos-like immunoreactivity after laryngeal-induced coughing and its reduction by codeine. J Neurosci 17: 9340-9352. doi:10.1523/JNEUROSCI.17-23-09340.1997

Gleeson K, Zwillich CW, White DP. 1990. The influence of increasing ventilatory effort on arousal from sleep. Am Rev Respir Dis 142: 295-300. doi:10.1164/ajrccm/142.2.295

Guyenet PG, Stornetta RL, Bayliss DA. 2010. Central respiratory chemoreception. J Comp Neurol 518: 3883-3906. doi:10 $.1002 /$ cne. 22435

Guyenet PG, Bayliss DA, Stornetta RL, Ludwig MG, Kumar NN, Shi Y, Burke PG, Kanbar R, Basting TM, Holloway $\mathrm{BB}$, et al. 2016. Proton detection and breathing regulation by the retrotrapezoid nucleus. J Physiol 594: 1529-1551. doi:10 $.1113 / \mathrm{JP} 271480$

Hennessy ML, Corcoran AE, Brust RD, Chang Y, Nattie EE, Dymecki SM. 2017. Activity of Tachykinin1-expressing Pet1 raphe neurons modulates the respiratory chemoreflex. JNeurosci 37: 1807-1819. doi:10.1523/JNEUROSCI.2316-16.2016

Herbert H, Moga MM, Saper CB. 1990. Connections of the parabrachial nucleus with the nucleus of the solitary tract and the medullary reticular formation in the rat. J Comp Neurol 293: 540-580. doi:10.1002/cne.902930404

Hodges MR, Best S, Richerson GB. 2011. Altered ventilatory and thermoregulatory control in male and female adult Pet-1 null mice. Respir Physiol Neurobiol 177: 133-140. doi:10 .1016/j.resp.2011.03.020

Kaur S, Pedersen NP, Yokota S, Hur EE, Fuller PM, Lazarus M, Chamberlin NL, Saper CB. 2013. Glutamatergic signaling from the parabrachial nucleus plays a critical role in hypercapnic arousal. J Neurosci 33: 7627-7640. doi:10.1523/JNEUR OSCI.0173-13.2013

Kaur S, Wang JL, Ferrari L, Thankachan S, Kroeger D, Venner A, Lazarus M, Wellman A, Arrigoni E, Fuller PM, et al. 2017. A genetically defined circuit for arousal from sleep during hypercapnia. Neuron 96: 1153-1167.e1155. doi:10.1016/j .neuron.2017.10.009

Lindsey BG, Nuding SC, Segers LS, Morris KF. 2018. Carotid bodies and the integrated cardiorespiratory response to hypoxia. Physiology (Bethesda, Md) 33: 281-297. doi:10.1152/phys iol.00014.2018

Lumsden T. 1923. Observations on the respiratory centres in the cat. J Physiol 57: 153-160. doi:10.1113/jphysiol.1923 .sp002052

Moga MM, Herbert H, Hurley KM, Yasui Y, Gray TS, Saper CB. 1990. Organization of cortical, basal forebrain, and hypothalamic afferents to the parabrachial nucleus in the rat. J Comp Neurol 295: 624-661. doi:10.1002/cne.902950408

Nurse CA, Piskuric NA. 2013. Signal processing at mammalian carotid body chemoreceptors. Semin Cell Dev Biol 24: 22-30. doi:10.1016/j.semcdb.2012.09.006

Olaithe M, Bucks RS, Hillman DR, Eastwood PR. 2018. Cognitive deficits in obstructive sleep apnea: insights from a metareview and comparison with deficits observed in COPD, insomnia, and sleep deprivation. Sleep Med Rev 38: 39-49. doi:10.1016/j.smrv.2017.03.005

Price JL, Amaral DG. 1981. An autoradiographic study of the projections of the central nucleus of the monkey amygdala. $J$ Neurosci 1: 1242-1259. doi:10.1523/JNEUROSCI.01-1101242.1981

Ray RS, Corcoran AE, Brust RD, Kim JC, Richerson GB, Nattie E, Dymecki SM. 2011. Impaired respiratory and body temperature control upon acute serotonergic neuron inhibition. Science 333: 637-642. doi:10.1126/science. 1205295

Saper CB, Loewy AD. 1980. Efferent connections of the parabrachial nucleus in the rat. Brain Res 197: 291-317. doi:10 .1016/0006-8993(80)91117-8

Severson CA, Wang W, Pieribone VA, Dohle CI, Richerson GB. 2003. Midbrain serotonergic neurons are central $\mathrm{pH}$ chemoreceptors. Nat Neurosci 6: 1139-1140. doi:10.1038/nn1130

Smith HR, Leibold NK, Rappoport DA, Ginapp CM, Purnell BS, Bode NM, Alberico SL, Kim YC, Audero E, Gross CT, et al. 2018. Dorsal raphe serotonin neurons mediate $\mathrm{CO}_{2}$-induced arousal from sleep. $J$ Neurosci 38: 1915-1925. doi:10.1523/ JNEUROSCI.2182-17.2018

Teppema LJ, Veening JG, Kranenburg A, Dahan A, Berkenbosch A, Olievier C. 1997. Expression of c-fos in the rat brainstem after exposure to hypoxia and to normoxic and hyperoxic hypercapnia. J Comp Neurol 388: 169-190. doi:10.1002/(SICI) 1096-9861(19971117)388:2<169::AID-CNE1>3.0.CO;2-\#

White DP. 2016. Pharmacologic approaches to the treatment of obstructive sleep apnea. Sleep Med Clin 11: 203-212. doi:10 $.1016 /$ j.jsmc.2016.01.007

White DP, Younes MK. 2012. Obstructive sleep apnea. Compr Physiol 2: 2541-2594. doi:10.1002/cphy.c110064 


\title{
$\$_{\text {CSH\& }}^{\infty}$ Cold Spring Harbor Symposia SYMPOSIA On Quantitative Biology
}

\section{Brain Circuitry for Arousal from Apnea}

\author{
Clifford B. Saper and Satvinder Kaur
}

Cold Spring Harb Symp Quant Biol 2018 83: 63-69 originally published online April 23, 2019 Access the most recent version at doi:10.1101/sqb.2018.83.038125

References This article cites 32 articles, 7 of which can be accessed free at: http://symposium.cshlp.org/content/83/63.full.html\#ref-list-1
Creative This article is distributed under the terms of the
Commons
License
http://creativecommons.org/licenses/by-nc/4.0/, which permits reuse and redistribution, except for commercial purposes, provided that the original author and source are credited.

Email Alerting
Service $\quad \begin{aligned} & \text { Receive free email alerts when new articles cite this article - sign up in } \\ & \text { the box at the top right corner of the article or click here. }\end{aligned}$ 